OPEN ACCESS

Edited by:

Ali Abdul-Sater,

York University, Canada

Reviewed by:

Yi Hao,

Huazhong University of Science and

Technology, China

Matthew Aaron Pettengill,

Thomas Jefferson University,

United States

*Correspondence:

Juan M. Zapata

jmzapata@iib.uam.es

tPresent Address:

Sophie Lefebvre,

Departements d'urgence et d'imagerie médicale, Montpellier

University Hospital, Montpellier,

France

John C. Reed, Sanofi,

Pharmaceuticals R\&D, 640 Memorial Drive, Boston, MA, United States

Specialty section:

This article was submitted to B Cell Biology,

a section of the journal

Frontiers in Immunology

Received: 01 September 2018 Accepted: 17 December 2018 Published: 11 January 2019

Citation:

Perez-Chacon G, Adrados M Vallejo-Cremades MT, Lefebvre S, Reed JC and Zapata JM (2019) Dysregulated TRAF3 and BCL2 Expression Promotes Multiple Classes of Mature Non-hodgkin B Cell Lymphoma in Mice.

Front. Immunol. 9:3114. doi: 10.3389/fimmu.2018.03114

\section{Dysregulated TRAF3 and BCL2 Expression Promotes Multiple Classes of Mature Non-hodgkin B Cell Lymphoma in Mice}

\author{
Gema Perez-Chacon ${ }^{1,2}$, Magdalena Adrados ${ }^{3}$, Maria T. Vallejo-Cremades ${ }^{2}$, \\ Sophie Lefebvre ${ }^{4 \dagger}$, John C. Reed ${ }^{4 \dagger}$ and Juan M. Zapata ${ }^{1,2 *}$
}

${ }^{1}$ Instituto de Investigaciones Biomédicas "Alberto Sols", CSIC-UAM, Madrid, Spain, ${ }^{2}$ Instituto de Investigación Hospital Universitario La Paz, Madrid, Spain, ${ }^{3}$ Instituto de Investigación del Hospital Universitario de La Princesa, Madrid, Spain, ${ }^{4}$ Sanford Burnham Prebys Medical Discovery Institute, La Jolla, CA, United States

TNF-Receptor Associated Factor (TRAF)-3 is a master regulator of B cell homeostasis and function. TRAF3 has been shown to bind and regulate various proteins involved in the control of innate and adaptive immune responses. Previous studies showed that TRAF3 overexpression renders B cells hyper-reactive to antigens and Toll-like receptor (TLR) agonists, while TRAF3 deficiency has been implicated in the development of a variety of B cell neoplasms. In this report, we show that transgenic mice overexpressing TRAF3 and BCL2 in B cells develop with high incidence severe lymphadenopathy, splenomegaly and lymphoid infiltrations into tissues and organs, which is the result of the growth of monoclonal and oligoclonal $B$ cell neoplasms, as demonstrated by analysis of $V_{H} D J_{H}$ gene rearrangement. FACS and immunohistochemical analyses show that different types of mature $\mathrm{B}$ cell neoplasms arise in TRAF3/BCL2 double-transgenic (tg) mice, all of which are characterized by the loss of surface IgM and IgD expression. However, two types of lymphomas are predominant: (1) mature B cell neoplasms consistent with diffuse large B cell lymphoma and (2) plasma cell neoplasms. The Ig isotypes expressed by the expanded B-cell clones included IgA, IgG, and IgM, with most having undergone somatic hypermutation. In contrast, mouse littermates representing all the other genotypes (TRAF3-/BCL2-; TRAF3+/BCL2-, and TRAF3-/BCL2+) did not develop significant lymphadenopathy or clonal $B$ cell expansions within the observation period of 20 months. Interestingly, a large representation of the HCDR3 sequences expressed in the TRAF3-tg and TRAF3/BCL2-double-tg B cells are highly similar to those recognizing pathogen-associated molecular patterns and damage-associated molecular patterns, strongly suggesting a role for TRAF3 in promoting B cell differentiation in response to these antigens. Finally, allotransplantation of either splenocytes or cell-containing ascites from lymphoma-bearing TRAF3/BCL2 mice into SCID/NOD immunodeficient mice showed efficient transfer of the parental expanded B-cell clones. Altogether, these results indicate that TRAF3, perhaps by promoting exacerbated $\mathrm{B}$ cell responses to certain antigens, and BCL2, presumably by supporting survival of these clones, cooperate to induce mature B cell neoplasms in transgenic mice.

Keywords: TRAF3, BCL2, DLBCL-diffuse large B cell lymphoma, plasma cell neoplasms, pathogen recognition receptors (PRRs), B cell lymphoma 


\section{INTRODUCTION}

Tumor Necrosis Factor Receptor (TNFR)-associated factors (TRAFs) constitute a family of scaffold proteins that interact with the cytoplasmic regions of various members of the TNFR superfamily upon their activation. TRAFs act as docking molecules for kinases, ubiquitin-ligases, ubiquitin-proteases and other effector proteins to comprise and modulate TNFRsignalosomes. In this regard, TRAFs regulate both the subcellular localization of the receptor-ligand complexes and the extent of the signaling response by controlling the composition and post-translational modification of proteins within these receptor signaling complexes. Additionally, some members of the TRAF family also regulate signaling and function of pattern recognition receptors (PRRs) and some interleukin-family receptors (1).

The role of TRAF-family proteins in regulating lymphocyte physiology and function is incompletely understood. This gap in knowledge is particularly relevant for TRAF3, which reportedly modulates multiple signaling pathways and plays a critical role in regulating $B$ cell survival, activation and differentiation $(2,3)$. With regards to adaptive immunity, for example, TRAF3 binds and regulates signaling by different TNFR family members in B-lymphocytes, including CD40, Bcell activating factor receptor (BAFFR), transmembrane activator and CAML interactor (TACI) and B-cell maturation antigen (BCMA), which are critical regulators of $\mathrm{B}$ cell proliferation, differentiation and survival $(4,5)$. Additionally, TRAF3 regulates Toll-like receptors (TLRs) through its interaction with myeloid differentiation primary response 88 (MyD88) and TIR-domaincontaining adapter-inducing interferon- $\beta$ (TRIF) (6), thereby participating in innate immune responses against pathogenassociated molecular patterns (PAMPs) and damage-associated molecular patterns (DAMPs) $(7,8)$. TRAF3 is also involved in the regulation of nucleotide-binding oligomerization domain (NOD)-like receptors (NLRs) and retinoic acid-inducible gene (RIG)-1-like Receptors (RLRs) through its interaction with receptor interacting protein (RIP)-2 (9) and mitochondrial antiviral-signaling (MAVS) protein (10), respectively, which are intracellular sensors of bacteria and virus products (11). Moreover, TRAF3 has also been shown to regulate IL17R signaling (12). Thus, TRAF3 is a pleiotropic protein controlling multiple pathways involved in the regulation of $\mathrm{B}$ cell proliferation, differentiation, survival with broad relevance to both adaptive, and innate immunity.

Probably because of its pleiotropic effects, TRAF3 has seemingly opposite functions in some cellular contexts. This is well-illustrated by analysis of B cell-specific Traf3-deficient mice (13) and lymphocyte-specific TRAF3-tg mice (14). B cell-specific Traf3-deficient mice develop B cell hyperplasia and have high Ig titers in serum, suggesting that endogenous TRAF3 might suppress B-cell expansion. In this regard, Traf3 deficiency in $B$ cells results in nuclear factor $\kappa \mathrm{B}$ (NF- $\kappa \mathrm{B})-2$ activation due to a role of endogenous TRAF3 in recruiting ubiquitin ligases that promote degradation of NK-kB-inducing kinase (NIK) (15), although the actual mechanism involved in TRAF3-mediated NIK regulation in B cells remains controversial (16). One of the consequences of TRAF3 deficiency (presumably attributed to the NF-kB2 over-activation) is the expansion of marginal zone (MZ) B cells $(13,17)$, which might explain the hyperreactivity to TLR ligands (18) and the systemic lupus erythematosus (SLE)like autoimmunity observed in these mice (13). MZ B cells do not normally express or have very reduced levels of TRAF3 expression (19) and are naturally overreactive to TLR ligands $(11,20)$. In contrast, lymphocyte-specific TRAF3-tg mice develop progressive plasmacytosis and hypergammaglobulinemia, show exacerbated TLR responses as well as increased IgG production in response to T-I and T-D antigens, and develop systemic inflammation and SLE-like autoimmunity (14). This phenotype suggests that TRAF3 over-expression also causes excessive Bcell function that can manifest as SLE-like autoimmunity, in this case perhaps by driving $\mathrm{B}$ cell differentiation to produce abundant antibody-secreting cells (ASCs) via a process that might speculatively be PRR-dependent.

TRAF3 has been proposed as a tumor suppressor protein since a number of biallelic deletions or inactivating mutations has been identified in human B cell malignancies, including B-chronic lymphocytic leukemia (CLL), splenic marginal zone lymphoma (SMZL), mantle cell lymphoma, diffuse large B-cell lymphoma (DLBCL), and multiple myeloma (MM), as well as in Waldenström's macroglobulinemia (21-27). In agreement with these results, B-cell-specific Traf3-deficient mice were reported to develop clonal SMZL or B1a lymphomas (28). These results are consistent with the hypothesis that TRAF3 inactivating mutations (resulting in constitutive NF- $\mathrm{KB} 2$ activation in B cells) predispose to malignant transformation irrespective of the $\mathrm{B}$ cell maturation state.

Previously, we have shown that lymphocyte-specific TRAF3tg mice have extra-nodal infiltration of B-cells into many organs and these animals experience an increased incidence of inflammation-driven solid tumors, including squamous cell carcinomas, lung carcinomas and hepatomas. However, these mice did not show formal evidence of B-lymphoid malignancy. Interestingly, intraperitoneal (I.P.) inoculation of pristane, a natural saturated terpenoid alkane known to promote autoimmune diseases and plasmacytoma in mice $(29,30)$, into TRAF3-tg mice resulted in increased tertiary organs formation and exacerbated autoimmunity, but other than a few cases of plasmacytoma, this treatment failed to promote manifest development of myeloma or other B-cell neoplasms (14). Taken together, these results suggest that TRAF3 upregulation causes severe alterations in B cell differentiation but is not sufficient to promote $\mathrm{B}$ cell transformation by itself.

Previously, we reported that mice with the combination of upregulated BCL2 and deficient TRAF2 signaling in B cells develop small B cell lymphoma (SBL)/CLL with high incidence, while neither deficient TRAF2 function nor BCL2 upregulation alone were sufficient to induce CLL or other malignancies in mice $(31,32)$. BCL2 overexpression is a landmark of CLL, follicular lymphoma (FL) and other B cell malignancies (33), including DLBCL (34). In this report, we show that the combination of TRAF3 and BCL2 overexpression in B cells leads over time to severe lymphadenopathy, splenomegaly and extranodal lymphoid infiltrations in tissues and organs in the mice, which is not observed in mice with mono-transgenic TRAF3 or BCL2. 
This dysplasia is the result of monoclonal and oligoclonal $\mathrm{B}$ cell neoplasms (as demonstrated by the analysis of rearranged $V_{H} D J_{H}$ genes). In addition, we show that TRAF3 upregulation favors the production of $V_{H} D J_{H}$ rearrangements producing HCDR3 sequences similar to those recognizing PAMPs and DAMPs.

\section{MATERIALS AND METHODS}

\section{Transgenic Mice}

Lymphocyte-specific TRAF3-tg (14) and B cell-specific BCL2tg mice mimicking the $\mathrm{t}(14 ; 18) \quad(\mathrm{q} 32 ; 21)$ chromosomal translocation involving $B C L 2$ and $I g H$ found in human FLs (35) have been previously described. TRAF3-tg (FVB/N) and $B C L 2-\operatorname{tg}(\mathrm{BALB} / \mathrm{c})$ heterozygous mice were bred to produce $\mathrm{F} 1$ litters with progeny of the four possible genotypes [(wild-type -/-; TRAF3-tg (single-positive +/-); BCL2-tg (single-positive $-/+$ ); and TRAF3/BCL2 (double-positive +/+)] expressed on $\mathrm{FVB} / \mathrm{N} \times \mathrm{BALB} / \mathrm{c}$ mixed background. Analysis of the transgenic mouse genotypes was performed by polymerase chain reaction (PCR) using primers specific for human

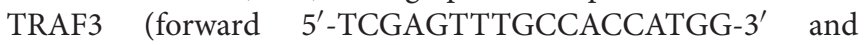
reverse $5^{\prime}$-GCGCGATCATCGGAACC-3') and BCL2 (forward 5'-TTAGAGAGTTGCTTTACGTGGCCTG-3' and reverse $5^{\prime}$ ACCTGAGGAGACGGTGACC- $3^{\prime}$ ). The animal protocols were approved by the Institutional Animal Care and Use Committees of the Sanford Burnham Prebys Medical Discovery Institute and by the Bioethics Committee of the Consejo Superior de Investigaciones Científicas. Mice showing symptoms of distress and pain (heavy breath, weight loss, lethargy, etc.) were euthanized. All transgenic mice in the study were heterozygotes for each transgene.

\section{Antibodies}

Antibodies against human TRAF3 (19) and BCL2 (36) were previously described. TRAF3 (C-20), CD10 (F-4), BCL6 (N-3), PCNA (FL-261), and ERK2 (C-14) were from Santa Cruz Biotechnologies. MUM-1 (ABIN721195, antibodies online), CD45R/B220 (14-0452-81, Thermofisher scientific), Ki67 (Ab15580, Abcam), cIAP1/2 (R\&D systems) and preadsorbed HRP-conjugated anti-mouse IgG (Sigma-Aldrich) and anti-mouse IgA (Novus biologicals) were used for western blot and/or immunohistochemistry analysis. Anti-rabbit and anti-mouse HRP-conjugated secondary antibodies were from Santa Cruz Biotechnologies or from Sigma-Aldrich. For flow cytometry analysis FITC- PE- and APC-labeled antibodies against mouse CD45R/B220, CD19, CD21, CD23, CD5, CD43, CD138/Syndecan-1, IgM, IgD, IgG (all from BD Biosciences) were used.

\section{Isolation of Mononuclear and B Cells}

Spleens, lymph nodes and blood from tg mice and WT littermates were collected and mononuclear cells were isolated by Ficoll density centrifugation (Lympholyte-M; Cedarlane Laboratories, Burlington, NC). B cells were isolated by negative magnetic selection using the StemSep mouse B cells enrichment kit (StemCells Technologies, Vancouver, CA), following the manufacturer's specifications.

\section{Flow Cytometry Analysis}

Mononuclear cells isolated as described earlier were incubated with $50 \mu \mathrm{g} / \mathrm{ml}$ human $\gamma$-globulin for $10 \mathrm{~min}$ at $4^{\circ} \mathrm{C}$. Then, $10^{6}$ cells were incubated with a combination of FITC-, PE-, or APCconjugated antibodies recognizing various surface markers. After 40 min of incubation at $4^{\circ} \mathrm{C}$, cells were washed with PBS and analyzed by flow cytometry in a FACS Canto II cytofluorimeter and the FlowJo (LLC) and FACSDiVa 6.1.2 (BD Biosciences) cytometry analysis softwares. Intracellular IgG expression was determined using a commercial fixation/permeabilization kit (Fitx\&Perm; Invitrogen Life Technologies), following the manufacturer's instructions.

\section{Immunohistochemistry}

Tissues and organs from transgenic mice were fixed in 10\% formalin (Sigma-Aldrich), embedded in paraffin. Tissue sections $(5 \mu \mathrm{m})$ were deparaffinized and antigen retrieval was then performed in citrate buffer solution $\mathrm{pH} 6$ (Dako). Sections were then rinsed with distilled water, treated $10 \mathrm{~min}$ at room temperature with peroxidase blocking solution $\left(10 \% \mathrm{H}_{2} \mathrm{O}_{2}\right.$ in methanol) and then washed with TBS. After blocking with a TBS buffer containing normal goat serum for $1 \mathrm{~h}$ at room temperature, the corresponding primary antibodies were applied to the sections over night at $4^{\circ} \mathrm{C}$. After washing with TBS, a HRP conjugated secondary antibody (Sigma Aldrich) was used to detect the primary antibody. Color was developed using a diaminobenzidine-based detection method (Vector Laboratories, Burlingame, CA), and sections were then counterstained with hematoxylin, dehydrated, and mounted in DPX (Fluka). Tissue sections were stained with hematoxylin and eosin (H\&E).

\section{Immunoblots}

Cells from different mouse tissues were lysed in modified Laemmli buffer $(0.125 \mathrm{M}$ Tris $\mathrm{pH} 6.8,4 \%$ SDS, and $20 \%$ glycerol) and sonicated. Protein concentration was determined by the bicinchoninic acid method (Pierce, Rockford, IL). Protein samples $(8-15 \mu \mathrm{g} /$ sample) were supplemented with 2.5\% 2-mercaptoethanol and $0.004 \%$ bromophenol blue, and subjected to SDS-PAGE analysis and immunoblotting, using the indicated primary antibodies and horseradish peroxidaseconjugated secondary antibodies. Specific bands were detected using enhanced chemiluminescence and exposure on film. ERK2 expression was used as an internal loading control.

\section{$V_{H} D J_{H}$ Analysis}

Tissues and cells from TRAF3xBCL2 mice representing all different genotypic combinations $(-/-;+/-;-/+$; and $+/+)$ were extracted and total RNA was isolated using TRI ZOL reagent and the PureLink ${ }^{\mathrm{TM}}$ RNA mini kit (Life Technologies, Carlsbad, CA), following the manufacturer's instructions. Then, RNA was reverse transcribed into cDNA using $2 \mathrm{U}$ Superscript II reverse transcriptase (Life Technologies). The IGHV regions were amplified using the following primers, $\mathrm{VH}$ primer (forward) $5^{\prime}$ SARGTBMAGCTGSAGSAGTCWGG-3'; $\mathrm{CH} \mu$ primer (reverse) 5'-CAGATCTCTGTTTTTGCCTCGTA-3'; $\mathrm{CH} \gamma$ primer (reverse) 5'-ATGCAAGGCTTACACCACAATCC-3'; and $\mathrm{CH} \alpha$ primer (reverse) 5' $5^{\prime}$-TAATAGGAGGAGGAGGAGTAGGAC-3' 
A

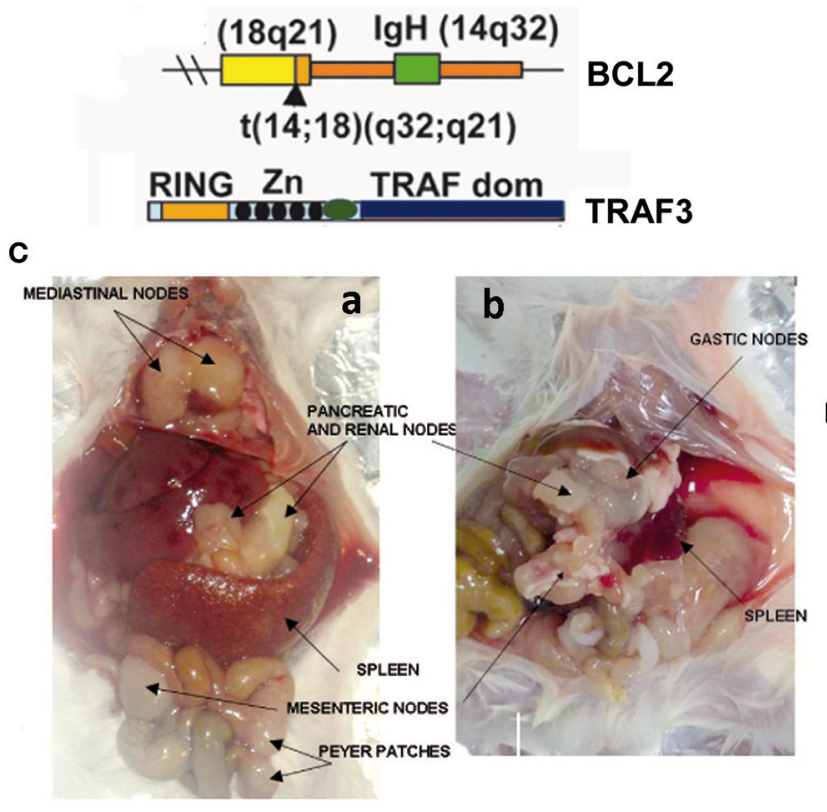

E
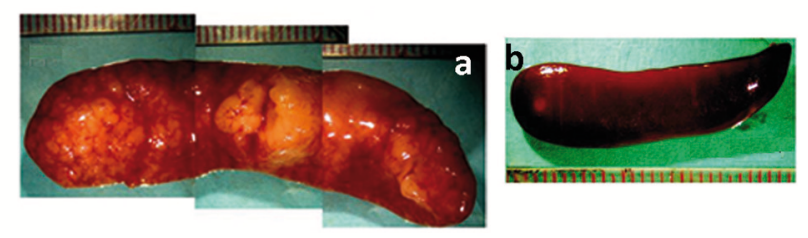

B

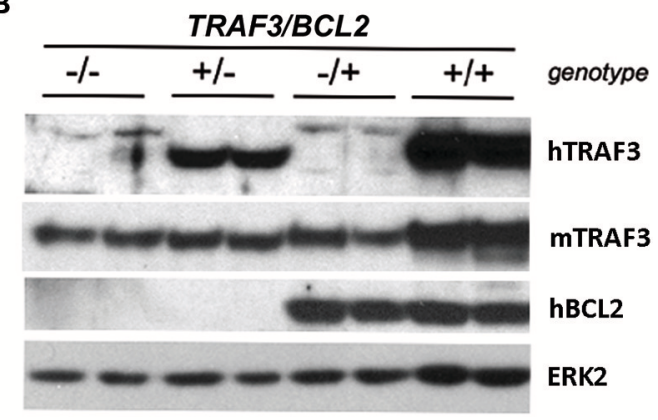

D

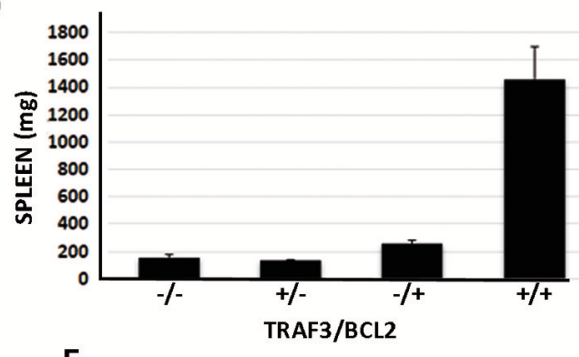

$\mathbf{F}$

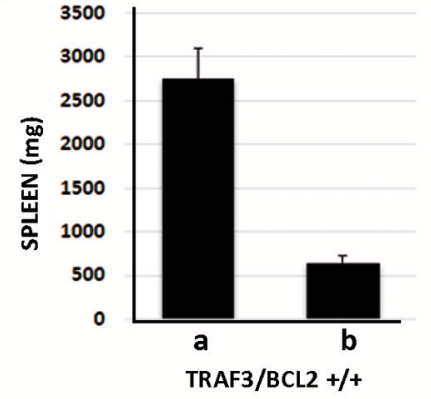

G
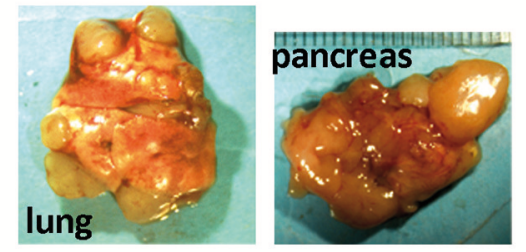

I

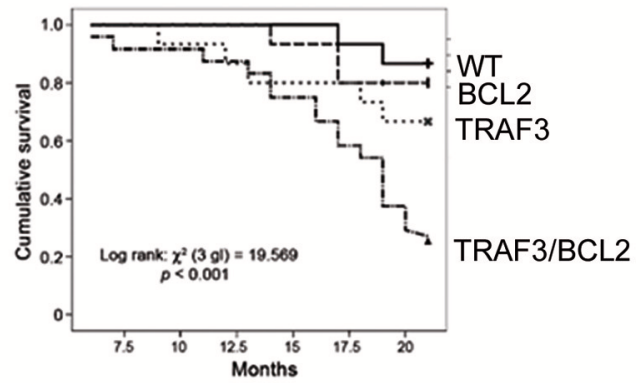

H
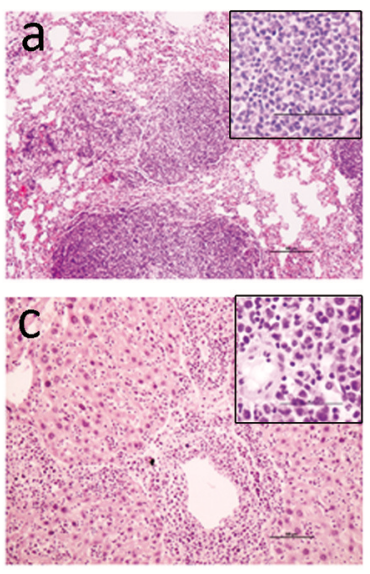
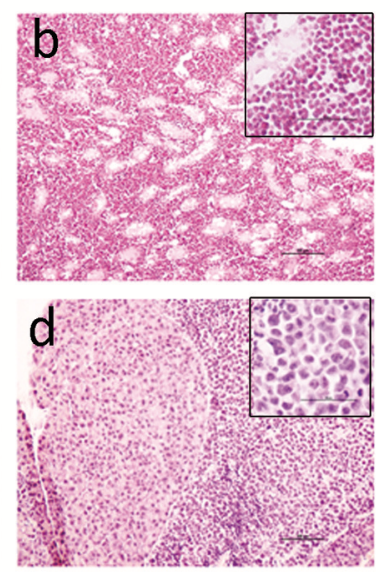

FIGURE 1 | TRAF3/BCL2 double-tg mice develop severe lymphoid dysplasias and have a reduced lifespan. (A) Schematic representation of the expressed transgenes. $B C L 2$ gene mimics the $\mathrm{t}(14 ; 18)(\mathrm{q} 32 ; \mathrm{q} 21)$ translocation involving $\mathrm{BCL} 2$ and IgH found in human FLs resulting in BCL2 overexpression. TRAF3 is under the control of the IgH promoter and the $\mu$ enhancer. (B) Representative examples of the TRAF3 and BCL2 expression in spleen extracts from mice with different TRAF3/BCL2 genotypes. Expression of ERK2 is used as loading control. (C) Representative examples of TRAF3/BCL2 double-tg mice with lymphoid dyscrasias. Mice usually develop two types of lymphadenopathies, group 1 characterized by massive splenomegaly and disseminated lymphadenopathy (a) and group 2 with moderate splenomegaly and disseminated lymphadenopathy (b). (D) Weight of the spleens of mouse littermates with the different TRAF3/BCL2 genotypes (-/-, $n=$ $7 ;+/-, n=10 ;-/+, n=10 ;+/+, n=32$ ). Mice were euthanized when $+/+$ mice developed lymphoid dyscrasias. Data represent mean \pm SEM. (E) Representative examples of the enlarged spleens developed by diseased TRAF3/BCL2-double-tg mice. The pictures illustrate the differences in aspect and morphology of group 1 (a) and group 2 (b) spleens. (F) Weight of the spleens of group 1 [(a), $n=13]$ and group $2[(\mathbf{b}), n=19]$. Mice were euthanized when $+/+$ mice developed lymphoid 
FIGURE 1 | dyscrasias. Data represent mean \pm SEM. (G) Representative examples of lungs (left) and pancreas (right) showing prominent lymphoid metastasis from TRAF3/BCL2-double-tg mice. (H) H \& E staining of tissues from representative TRAF3/BCL2-double-tg mice showing lymphoid infiltrations. Figure shows lungs (a), kidney (b), liver (c), and pancreas (d). Magnification is $100 \mathrm{x}$. The square inside shows a $400 \mathrm{x}$ magnification capture of the infiltrating lymphocytes. Scale bars are shown. (I) Kaplan-Meier analysis of survival of mice with the different TRAF3/BCL2 genotypes $(-/-, n=15 ;+/-, n=15 ;-/+, n=15 ;+/+, n=24)$. Survival analysis was performed by using the nonparametric model of Kaplan-Meier. Log-rank test analysis of TRAF3/BCL2 double-tg mice survival compared to the other groups demonstrated statistical significance (vs. wild-type, 0.0005; vs. TRAF3-tg, 0.029; vs. BCL2-tg, 0.002).

(Life Technologies). After denaturing DNA at $94^{\circ} \mathrm{C}$ for $10 \mathrm{~min}$, the PCR conditions entailed 38 cycles of denaturing at $94^{\circ} \mathrm{C}$ for $1 \mathrm{~min}$, annealing at $52^{\circ} \mathrm{C}$ for $1 \mathrm{~min}$ and extension at $68^{\circ} \mathrm{C}$ for $1 \mathrm{~min}$, with a final extension step at $68^{\circ} \mathrm{C}$ for $10 \mathrm{~min}$. The PCR products were then analyzed by gel electrophoresis in a $2 \%$ agarose gel, excised and purified (Qiagen). Purified products were cloned using the pGEM $^{\circledR}-\mathrm{T}$ Vector System (Promega, Madison, WI, USA) and transformed into bacteria, following the manufacturer's instructions. From 5 to 15 bacterial colonies of each sample were grown in culture overnight and the plasmids were extracted using the Wizard ${ }^{\circledR}$ Plus SV Minipreps DNA Purification System (Promega). Sequencing was performed by GATC Biotech (Konstanz, Germany). Nucleotide sequences were analyzed by means of Chromas 2.4.3 software (Technelysium, Queensland, Australia) and compared with those mouse germ-line sequences available in the IMGT/V-QUEST databases $(37,38)$. Sequences with $<97.5 \%$ identity to the corresponding germ-line IGHV sequence were considered as mutated. Isolectric point (pI) of HCDR3 region was calculated with the Compute $\mathrm{pI} / \mathrm{Mw}$ tool (ExPASy Bioinformatics Resource Portal, http://web.expasy.org/compute_ pi/). HCDR3 analysis was carried out comparing the sequence in the protein BLAST database (restricted to Mus musculus sequences). Only sequences with at least $75 \%$ identity were considered.

\section{Adoptive Transfer}

Splenocytes or lymphocytes isolated from lymph nodes, ascites or pleural effusion $\left(40-60 \times 10^{6}\right)$ from representative TRAF3/BCL2 double-tg mice with lymphoma were I.P. allo-transplanted into 8-12 weeks-old non-obese diabetic/severe combined immunodeficiency (NOD/SCID) mice. Animals were euthanized when the mice develop sign of illness (distended belly, respiratory distress, lethargy, etc).

\section{Statistical Analysis}

Survival analyses were performed using the Kaplan-Meier method and the log-rank test. Differences were regarded as significant when $p<0.05$.

\section{RESULTS}

\section{TRAF3/BCL2 Double-tg Mice Develop Severe Lymphoid Dysplasia and Have a Reduced Lifespan}

To assess whether TRAF3 upregulation might contribute to B cell transformation, we crossed lymphocyte-specific TRAF3tg mice (14) with B cell-specific BCL2-tg mice (35). A schematic representation of the expressed transgenes is shown in Figure 1A. TRAF3-tg (FVB/N background) and BCL2-tg (BALB/c background) mice were crossed to produce F1 litters with mice harboring the different transgene combinations, TRAF3/BCL2 -/-, +/-, -/+, and +/+. Immunoblot analysis of spleen extracts from mice bearing the TRAF3 and BCL2 transgenes readily demonstrated the expression of TRAF3 and BCL2. Moreover, hTRAF3 did not alter the expression of endogenous mTRAF3 (Figure 1B). Young TRAF3/BCL2 double$\operatorname{tg}$ mice did not show any significant alteration other than modest splenomegaly, which was similar to that of the BCL2-tg mice (31). However, when TRAF3/BCL2 double-tg mice became older they began developing severe lymphoid dyscrasias, characterized by massive splenomegaly, and overt disseminated lymphadenopathy (Figure 1C). Some of the mice also develop pleural effusions and ascites. In contrast, these pathologies were not found in littermates of the other genotypes as they aged (Figure 1D and data not shown).

Interestingly, we observed a pattern in the size and shape of the spleens of the TRAF3/BCL2 double-tg mice that developed lymphoid pathologies. Many spleens were extremely large, ranging from 1.5 to $5.8 \mathrm{~g}$, with a pale appearance suggestive of an accumulation of white blood cells disproportionally to red blood cells. The spleens grossly had a lumpy surface and patchy decolorized zones suggestive of large lymphoid nodules (Figures 1E,Fa). Alternatively, spleens from some animals were larger than normal (0.3-1.2 g) but with a grossly normal appearance (Figures 1E,Fb).

Lymphadenopathy could be found in the double transgenic mice irrespective of gross splenic morphology (Figure 1C). In addition, diseased TRAF3/BCL2 double-tg mice show massive lymphoid infiltrations in a variety of organs that often could be seen on gross pathological examination (Figure 1G). Histopathology studies confirmed the severe lymphoid infiltration of various tissues and organs (Figure $\mathbf{1 H}$ ), including lung (Figure 1Ha), kidney (Figure 1Hb), liver (Figure 1Hc), and pancreas (Figure 1Hd). Consistent with the lymphoproliferative pathology observed in the TRAF3/BCL2 double-tg mice, these animals also have a significantly shorter lifespan than their littermates with wild-type, BCL2-tg, and TRAF3-tg genotypes (Figure 1I).

\section{DLBCL and Plasma Cell Neoplasms Are the Most Common Types of B Cell Dyscrasias Developed by TRAF3/BCL2 Double-tg Mice}

Flow cytometry analysis of the lymphoid populations from lymphoid tissues of diseased TRAF3/BCL2 double-tg mice, including spleen, nodes, blood, as well as ascites, and pleural effusion when found in the mice, showed that they were 


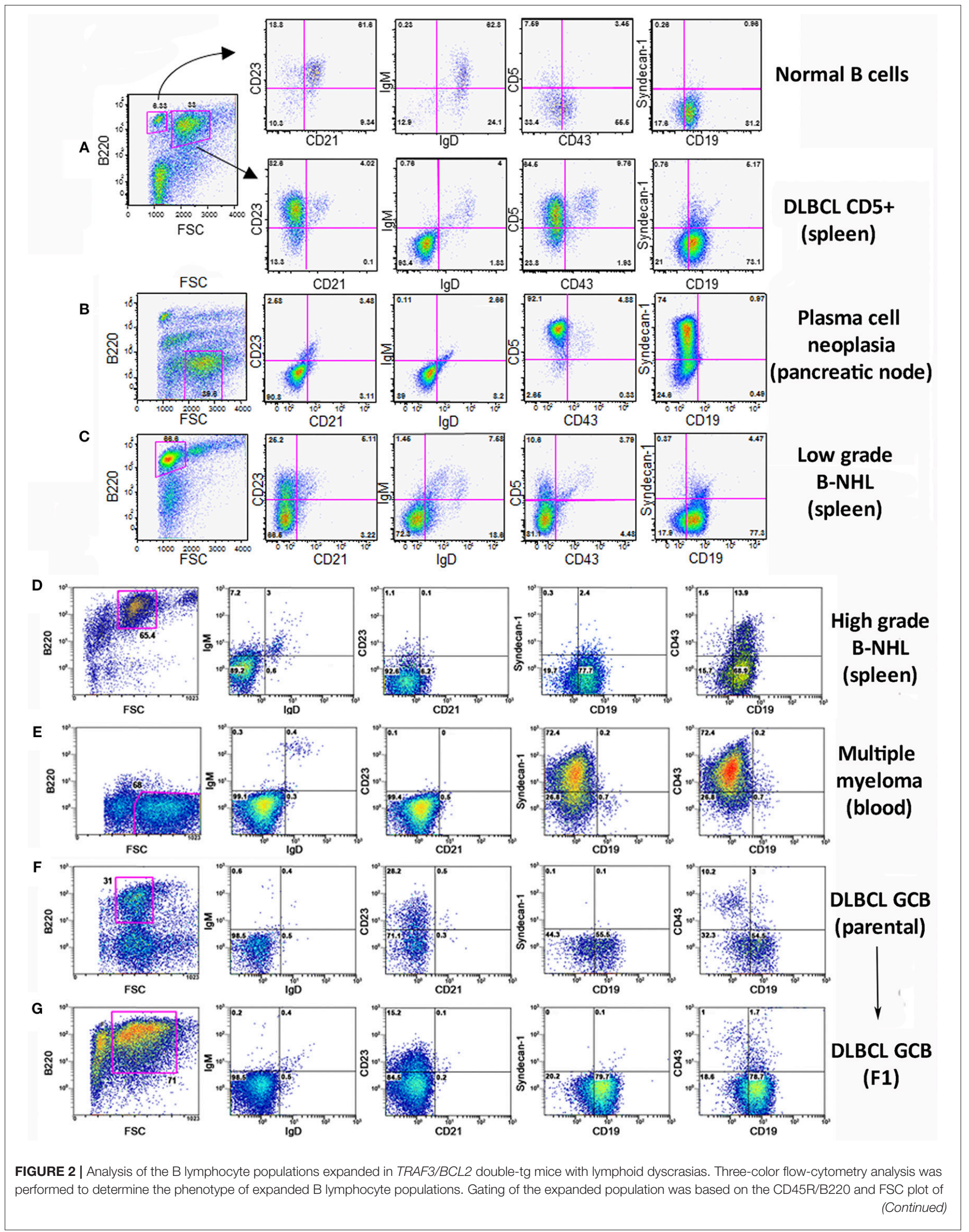


FIGURE 2 | each sample analyzed and is indicated in the figure. The surface molecules analyzed are indicated in the plots, as well as the percentage of cells found in each quadrant. The quadrants settings were selected based on the staining of isotype-controls (not shown). The tissue source where the analyzed lymphocytes were extracted from and the type of B cell malignancy developed by the TRAF3/BCL2 double-tg mice, according to the flow-cytometry and immunohistochemical analysis, is indicated in the figure.

consistently composed by B cell expansions with distinct surface marker expression but all indicative of a mature B cell phenotype. Representative examples are shown in Figure 2. Our results indicated that the vast majority of these $\mathrm{B}$ cell populations could be allocated into two major groups. The first group was characterized by large cells $\left(\mathrm{FSC}^{\mathrm{H}}\right.$ ) expressing CD45R/B220 and CD19, but having lost surface IgM, IgD, and CD21 expression (Figures 2A,D,F,G). The other group was composed by large cells lacking CD45R/B220, CD19, CD21, CD23, IgM, and IgD on their surface but expressing syndecan-1 (CD138) (Figures 2B,E, 4A), which is indicative of plasma cell lineage. In addition, a few mice developed a type of lymphoid expansion composed by small B cells expressing CD45R/B220 and CD19 and lacking the expression of CD21, CD23, IgM, and $\operatorname{IgD}$ on their surface (Figure 2C). For comparison, Figure 2A, top, shows the surface markers expression analysis of the remaining normal $\mathrm{B}$ cell population present in the spleen of that mouse.

Sequencing of the $V_{H} D J_{H}$ region of the heavy chain $(\mathrm{IgH})$ gene locus (deduced from the transcriptome) showed that both the large B-cell and the plasma cell types of lymphoid expansions were either monoclonal or oligoclonal (Table 1), thus indicating that the TRAF3/BCL2 double-tg mice develop lymphoid neoplasms. Further characterization of the $B$ cell neoplasms developed by these mice was accomplished by immunohistochemistry. These results further confirm the expression in these neoplasms of TRAF3 (which was more often located in the nucleus than in the cytoplasm), and BCL2 (which was present in the cytosol) (Figure 3 and Supplementary Figures 1-3). Moreover, based on the differential expression of MUM-1, BCL6, and CD10, we conclude that most of the lymphoid neoplasms characterized by very large spleens were consistent with DLBCL. Figure 3 shows a DLBCL expressing $\mathrm{BCL}^{+}, \mathrm{MUM}-1^{\text {null }}$ and $\mathrm{CD} 10^{\text {null }}$, representative of the GC B cell cluster. Other examples of DLBCL are shown in Supplementary Figure 1. In the DLBCL group, which is characterized by large cells $\left(\mathrm{FSC}^{\mathrm{H}}\right.$ ) expressing CD45R/B220 and CD19, we also found examples of mice with B cell neoplasms showing a prominent starry sky pattern, positive staining for BCL6, MUM-1, and CD10 and a high proliferation index, as shown by Ki67 staining, consistent with a high-grade B-non Hodgkin lymphoma (NHL) (Supplementary Figure 2). Of note is that this later lymphoma also has c-MYC overexpression (not shown). Interestingly, one mouse developed a B cell neoplasm consistent with a rare type of DLBCL expressing CD5 (Figure 2A). Immunohistochemical analysis of representative examples of the plasmacytoid neoplasms confirmed expression of either cytosolic IgG or IgA and showed a high Ki67 proliferation index $(>50 \%)$, consistent with a plasma cell neoplasia (Figure 3 and Supplementary Figure 3). Consistent with this diagnosis, some neoplasms of this group also express cytosolic IgG as demonstrated by FACS and immunoblotting of protein extracts of lymphoid tissues from representative TRAF3/BCL2 double$\operatorname{tg}$ mice with this type of lymphoid expansions (Figure 4). A diagram representing the frequency of the different $B$ cell neoplasms found in the TRAF3/BCL2 double-tg mice is provided in Figure 3.

\section{TRAF3/BCL2 Double-tg Mice Develop Clonal B Cell Expansions}

As indicated above, the analysis of the $V_{H} D J_{H}$ rearrangements confirmed the existence of clonal $\mathrm{B}$ cell expansions in the TRAF3/BCL2 double-tg mice observed with aging (Table 1). The expanded clones were mono- or oligoclonal and the Ig subtypes of these clones varied (IgA, IgG, and IgM were observed). In addition, somatic hypermutation (SHM) took place in approximately half of the IgM clones and most (75-80\%) of the $\operatorname{IgA}$ and $\operatorname{IgG}$ clones. The fact that most of these clones have experienced Ig class switching and SHM suggests that these neoplasms arise from antigen-activated B cells that have undergone differentiation in germinal centers (GCs), although extra-follicular differentiation is also a possibility, in particular for those clones expressing IgM. In some instances, distinct clonal expansions were found in different lymphoid tissues of the same mouse, as indicated by the Ig subclass and the HCDR3 sequence of the expanded clones (Table 1).

As one hallmark of cancer is the ability of tumor cells to grow into immunodeficient recipients after transplantation, we used splenocytes or lymphocytes from either ascitic fluid or pleural effusion for allo-transplantation into SCID/NOD immunodeficient mice (Table 2). For these experiments we used lymphocytes from mice representing three of the most characteristic of the $B$ cell neoplasms developed by the TRAF3/BCL2 double-tg mice. One of the donor mice (\#3) developed splenomegaly $(1,200 \mathrm{mg})$, severe diffuse lymphadenopathy $(5,000 \mathrm{mg})$ and ascitic fluid. FACS analysis (Figure 2D) and immunohistochemistry (Supplementary Figure 2) of the spleen was consistent with a high-grade B-NHL. A major IgA clone was found in spleen and ascites, although other polyclonal IgM, IgG, and $\operatorname{IgA}$ populations were also found, in particular in ascitic fluid (Supplementary Figure 4). In addition, the analysis of a node from this mouse showed the existence of an expanded clone (IgM) different to that found in spleen and ascites (Table 1). Allo-transplantation of ascitic lymphocytes from mouse \#3 resulted in efficient implantation, taking only 3-4 weeks for the development of overt lymphoma in recipient mice. Necropsies showed that recipient SCID/NOD mice had massive lymphadenopathy and ascitic fluid but fairly normal spleens (Table 2). A similar result was obtained when ascites from one F1 transplanted mouse was transferred to another SCID/NOD recipient (F2). The analysis of the IgM, IgG, and IgA populations in the recipient mice showed a striking enrichment of the 


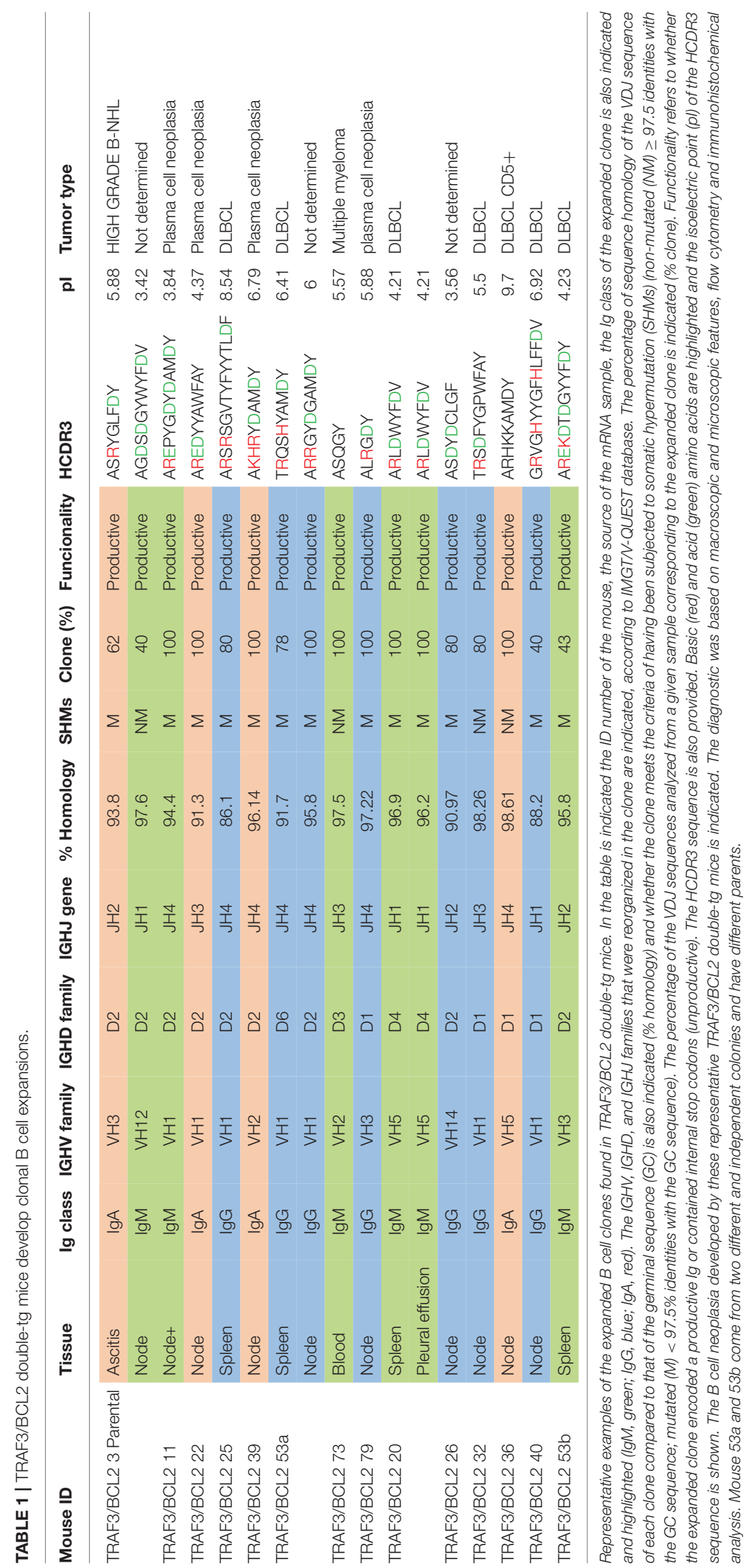



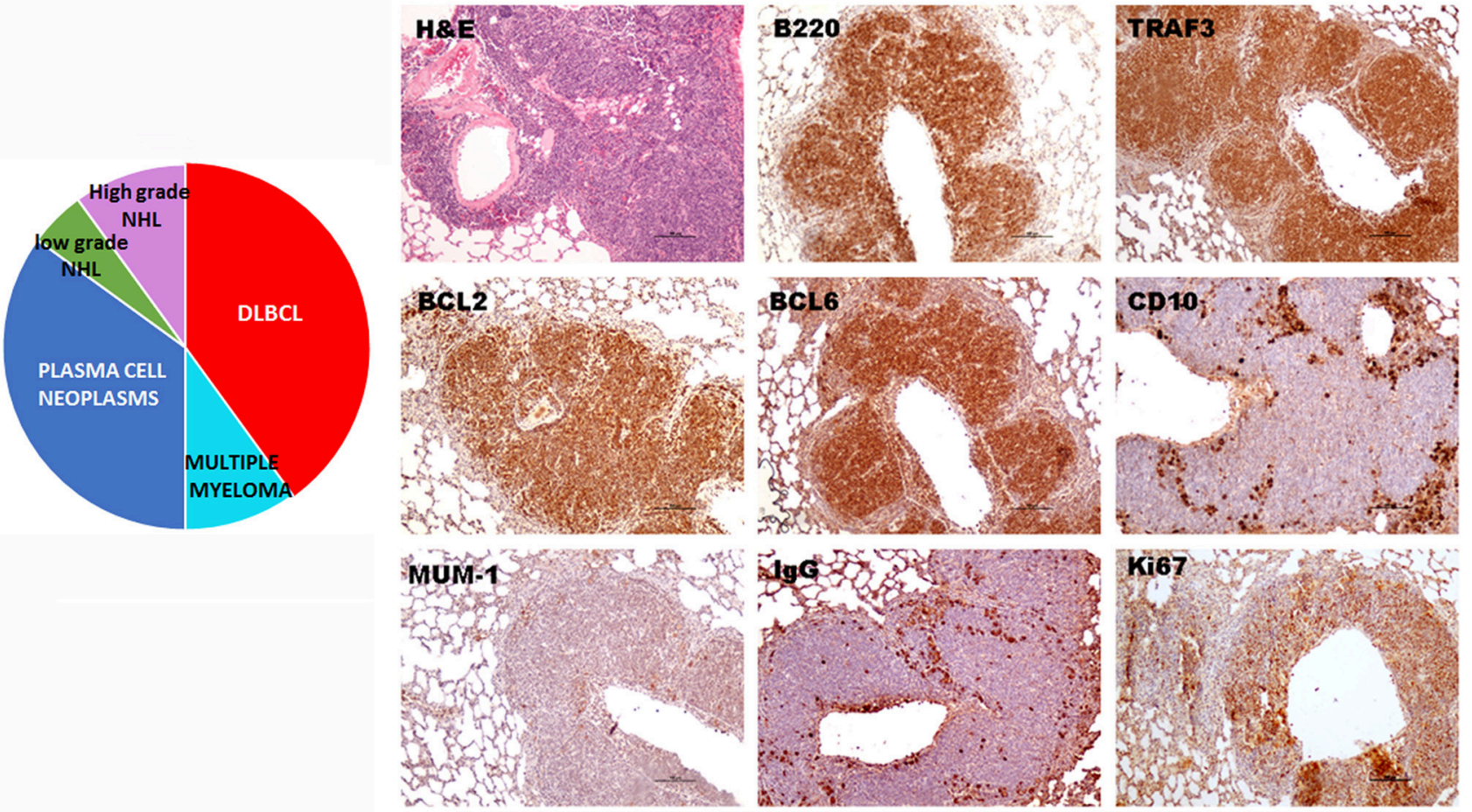

\section{Plasma cell neoplasm}
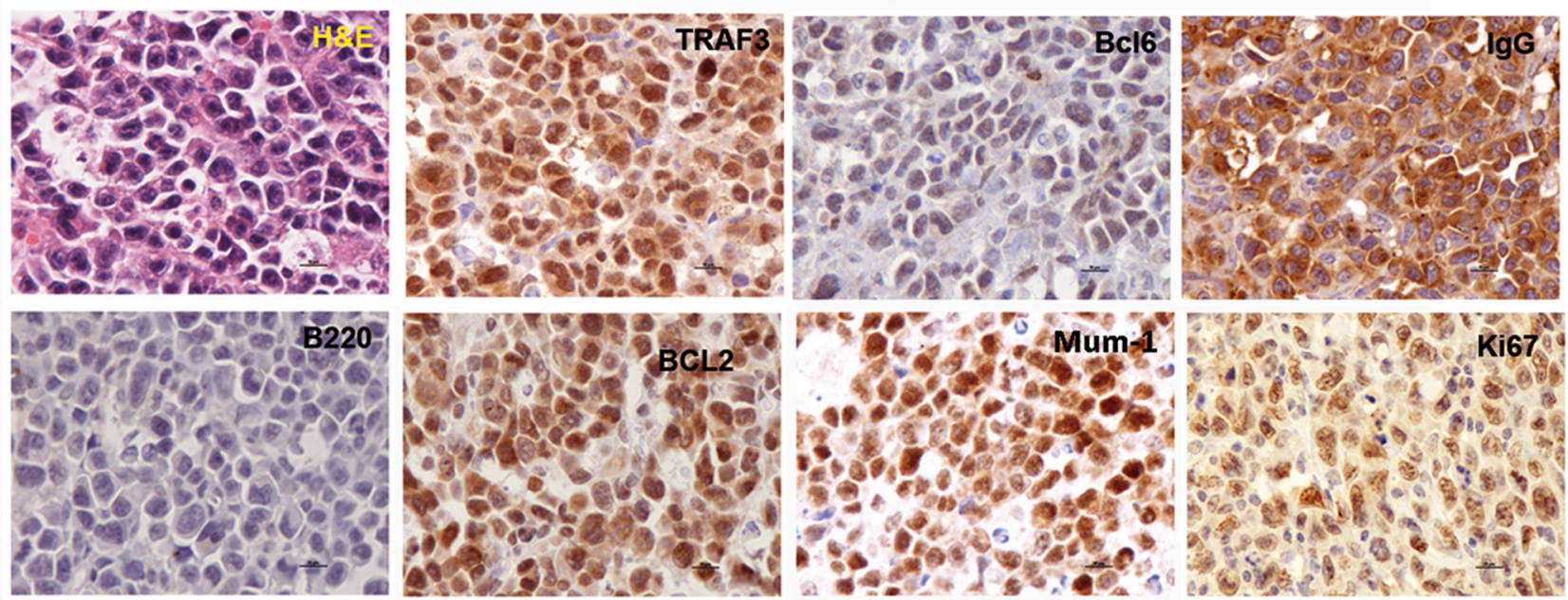

FIGURE 3 | TRAF3/BCL2 double-tg mice develop different types of mature B cell neoplasias, but predominantly DLBCL and plasma cell neoplasias. Immunohistochemical analysis of representative examples of a DLBCL GCB type and a plasma cell neoplasia developed by the TRAF3/BCL2 double-tg mice. Tissue slides were stained either with H\&E or with antibodies specific for human TRAF3 and BCL2 and for mouse CD45B220, BCL6, MUM-1, CD10, IgG and Ki67, as indicated. Scale bars are $100 \mu \mathrm{m}$ (DLBCL) and $10 \mu \mathrm{m}$ (plasma cell neoplasia). A diagram indicating the frequency of the different lymphoid neoplasias found in the TRAF3/BCL2 double-tg mice is shown $(n=18)$.

IgA population in the lymphoid tissues from $\mathrm{F} 1$ and $\mathrm{F} 2$ mice (Supplementary Figure 4). The analysis of the rearranged $V_{H} D J_{H}$ sequences showed that the major parental expanded clone (IgA) found in spleen and ascites of the donor mouse was the only clone detected in the F1 and F2 allotransplanted mice (Table 2). A similar result was obtained when lymphocytes from mouse \#20 were used for allo-transplantation. Mouse \#20 developed a monoclonal IgM neoplasia consistent with DLBCL. The transfer of splenocytes or ascitic lymphocytes from this mouse into recipient SCID/NOD mice resulted in the expansion 


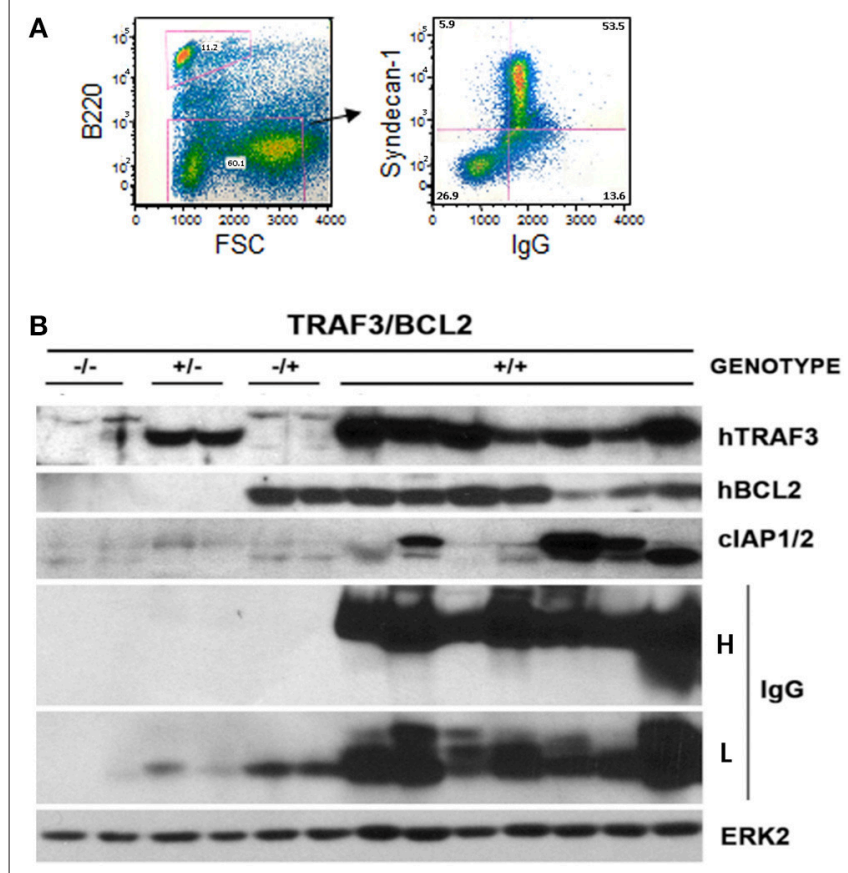

FIGURE 4 | Development of plasmablastic B cell neoplasms by TRAF3/BCL2 double-tg mice. (A) Flow cytometry analysis of a representative TRAF3/BCL2 double-tg mouse showing the expansion of an FSChigh CD45B220null lymphoid population with surface syndecan-1 (CD138) and cytosolic IgG expression. (B) Western blot analysis of lymphoid extracts (spleens and nodes) of representative examples of TRAF3/BCL2 double-tg (+/+) mice that have developed plasma cell neoplasms. For comparison, 2 representative examples of spleen extract from wild-type (-/-), TRAF3-tg (+/-), and BCL2-tg (-/+) mice is also shown. The expression of human TRAF3 and BCL2, and mouse ClAP1/2 and lgG heavy $H$ and light $L$ chains is shown. ERK2 expression is shown as loading control.

of the parental expanded clone (Table 2) and the development of a lymphoma that recapitulated the characteristics of the parental neoplasm (Figures 2F,G). Finally, we also allo-transplanted lymphocytes of mouse \#39, which developed lymphadenopathy and ascites, consistent with a plasma cell neoplasia caused by the expansion of an IgA clone (Supplementary Figure 3). Although in this case the tumor implantation took longer, the recipient immunodeficient mouse developed the same neoplasm and clonal IgA expansion than the donor mouse (Table 2).

\section{TRAF3-tg and TRAF3/BCL2 Double-tg Mice Have a Large Representation of B Cells With Rearranged HCDR3 With Similarities to Those Recognizing PAMPS and DAMPs}

We analyzed the HCDR3 sequences obtained from the TRAF3/BCL2 double-tg mice in an effort to determine the potential antigens recognized by these clones (39), making comparisons with HCDR3 sequences obtained from littermates of the other genotypes (wild-type, TRAF3-tg, and BCL2-tg). Only
HCDR3 sequences with $\geq 75 \%$ identities to antigen-matched HCDR3 sequences were considered for these analyses.

As shown in Figure 5, TRAF3-tg and TRAF3/BCL2double-tg mice have a remarkable percentage of $V_{H} D J_{H}$ rearrangements producing HCDR3 potentially recognizing DAMPs (including nuclear antigens, DNA), and PAMPs (including phosphatidylcholine, lipoteichoic acid and other bacteria, mite and virus antigens). In contrast, the representation of HCDR3 sequences recognizing these types of antigens is much reduced in wild-type and BCL2-tg littermates, thus underscoring the key role of TRAF3 in promoting humoral responses against these antigens. Remarkably, a highly represented group of HCDR3 sequences found in the TRAF3-tg and TRAF3/BCL2 double-tg mice (12.5 and 9.5\% of the clones, respectively) had high similarities to HCDR3 recognizing anti-nuclear antigens. The presence of clones expressing autoreactive Ig, such as anti-nuclear antibodies (ANAs) is also consistent with the involvement of TRAF3 in the development of autoimmune disorders and confirms previous results showing the existence of ANAs in the serum of the TRAF3-tg mice (14). The expanded TRAF3/BCL2 double-tg clones maintained this trend and have HCDR3 sequences similar to those recognizing viral antigens, nuclear antigens, DNA and phosphatidylcholine (Figure 5). Consistent with the role of some of these antibodies in autoimmunity, TRAF3/BCL2 double-tg mice also develop autoimmune lesions, such as IgG depositions in glomeruli and tertiary lymphoid organs formation (Figure 6).

\section{DISCUSSION}

In this report, we show that TRAF3 and BCL2 cooperate to promote development of a variety of mature B cell lymphomas arising from antigen-challenged B cells. In this process, TRAF3 seems to promote antigen-dependent B cell differentiation toward ASCs, and BCL2 seems to provide the survival tools required to facilitate $B$ cell transformation and survival of the expanded clones. Neither TRAF3 nor BCL2 alone have the capacity to support $B$ cell transformation to the same extent that is achieved when both TRAF3 and BCL2 act in combination. Indeed, BCL2-tg mice have been shown to develop FL with advanced aging at an approximately 15\% incidence (35), although these mice are otherwise healthy and have a normal life-span. In contrast, TRAF3-tg mice develop several pathologies associated to inflammation and autoimmunity, including inflammation-driven solid tumors, but very rarely develop lymphoid malignancies (14).

As shown in this report, lymphoid-specific TRAF3/BCL2 double-tg mice develop B cell neoplasms, mostly DLBCL and plasma cell neoplasia, with high incidence (approximately $80 \%$ of the mice). However, the fact that these B cell malignancies arise in mice well over 1 year old suggests that TRAF3 and BCL2 might be necessary but are not sufficient for B cell transformation, and that additional transforming events are required. Nevertheless, given the high incidence of $B$ cell tumors developed by the TRAF3/BCL2 double-tg mice, the 


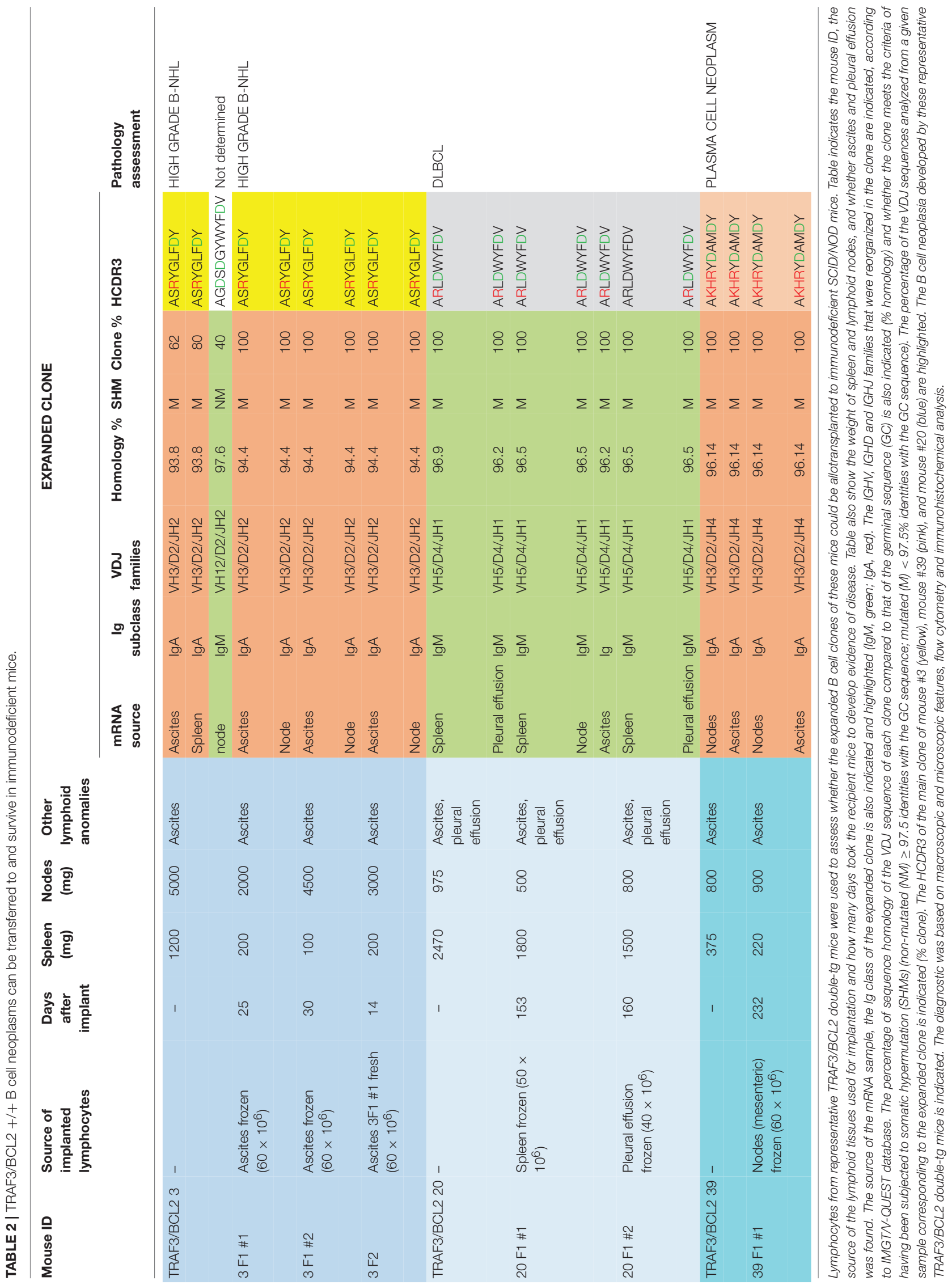




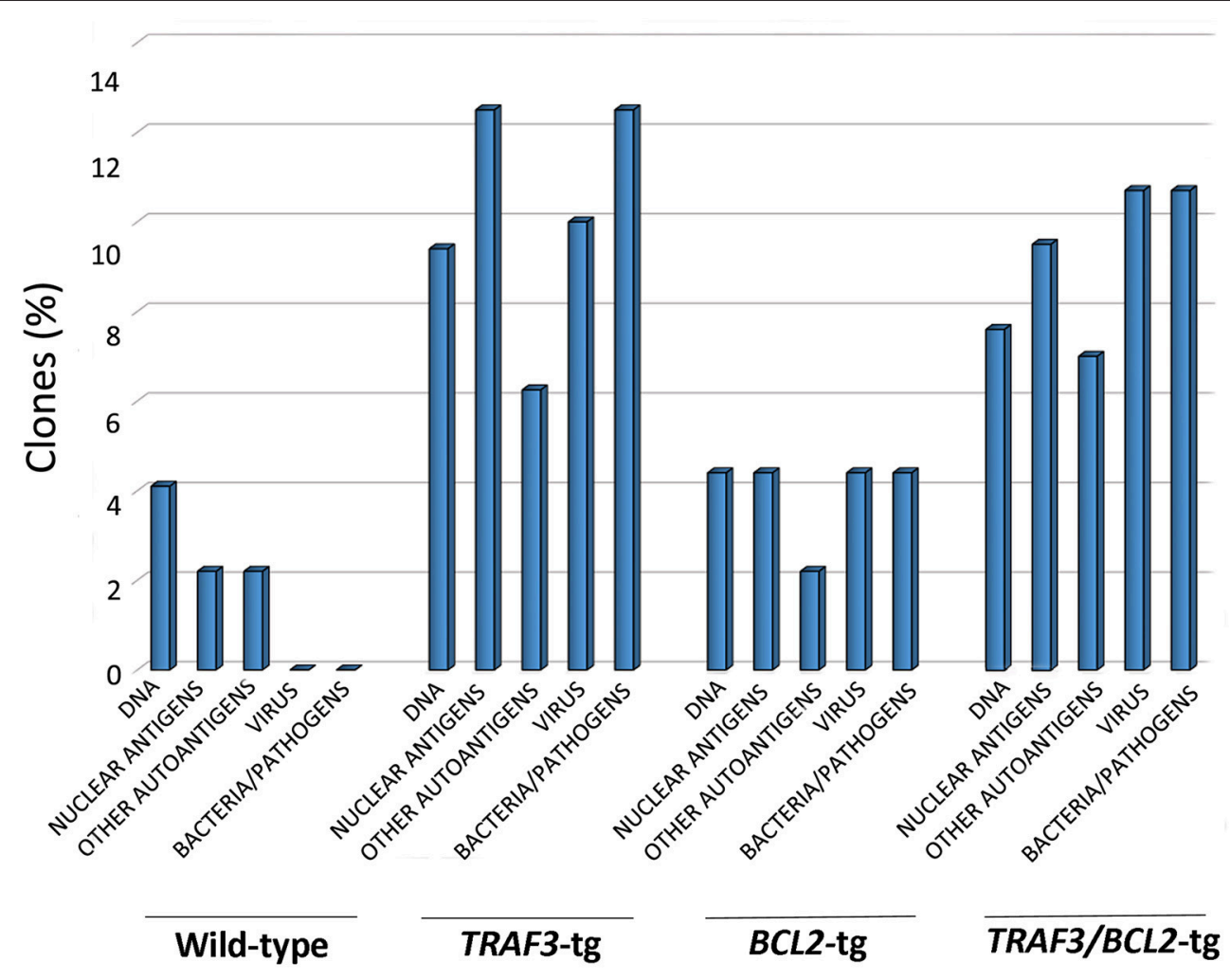

FIGURE 5 | TRAF3 upregulation increases the incidence of immunoglobulins with HCDR3 sequences potentially reactive to autoantigens and PAMPs. HCDR3 sequences were analyzed by blastp (non-redundant protein sequences from Mus musculus) and those showing $\geq 75 \%$ identity to described sequences recognizing DNA, ANAs, other autoantigens, and PAMPs (virus, bacteria, and other pathogens) were selected. Data represents the percentage of HCDR3 sequences similar to those recognizing the indicated antigens.

overexpression of both transgenes might favor the occurrence of these additional transforming events. In this regard, upregulation of c-MYC expression has been observed in two TRAF3/BCL2 double-tg mice that have developed high grade B NHL.

It is noteworthy that many of the B cell lymphomas arising in the TRAF3/BCL2 double-tg mice show a nuclear localization of TRAF3. Recently, studies showed that TRAF3 can traffic into the nucleus where it associates with and inhibits the transcriptional regulator CAMP response element binding protein (CREB) (35). CREB-binding protein (CREBBP) is a key coactivator of CREB transcriptional function (40) and this gene is frequently mutated in FL and DLBCL (41). Remarkably, mice deficient in Crebbp have reduced $B$ cell numbers affecting different $B$ cell subsets. However, BCL2 can overcome these deficiencies and collaborate with Crebbp loss to promote DLBCL development, as shown in mice where both Crebbp gene inactivation and BCL2 overexpression in B cells were combined (42). Interestingly, cMYC expression is upregulated and seems to play a crucial role in the $\mathrm{B}$ cell transformation process in this mouse model, thus underlining some similarities to the high-grade B NHLs developed by some TRAF3/BCL2 double-tg mice.

Our results indicate that both lymphocyte-specific TRAF3$\operatorname{tg}$ and TRAF3/BCL2 double-tg mice have a large representation of $V_{H} D J_{H}$ rearrangements producing HCDR3 sequences highly similar to those recognizing PAMPs and DAMPs, including DNA, nuclear antigens, and other autoantigens (platelet glycoproteins, hemoglobin and myosin, among others), bacteria antigens (including phosphatidylcholine and lipoteichoic acid), virus, and other parasite antigens. In contrast, wild-type and BCL2-tg littermates sharing cages with the TRAF3-tg and TRAF3/BCL2 double-tg and therefore being exposed to the same antigens have significantly fewer of these HCDR3 sequences, thus underscoring TRAF3 involvement in this process. These results are consistent with the participation of TRAF3 in the regulation of several PRRs involved in the innate immune responses to PAMPs and DAMPs. Indeed, a role for TRAF3 in controlling TLR and RLR-mediated interferon (IFN) responses against virus is well-documented $(43,44)$ and many examples of viral proteins have been identified that subvert TRAF3 antiviral function by targeting it or by out-competing TRAF3 binding to its signaling partners $(45,46)$. Furthermore, TRAF3 overexpression in B cells induced exacerbated TLR-mediated antibody responses (14). This is consistent with the role of TLRs in humoral responses against bacteria and other pathogens (47) and with the involvement of TRAF3-binding partner MyD88 in promoting robust TLR-mediated B cell humoral responses to virus (48). However, TLR hyper-responsiveness have been also shown in Traf3-deficient B cells (18). These seemingly opposite results 
A
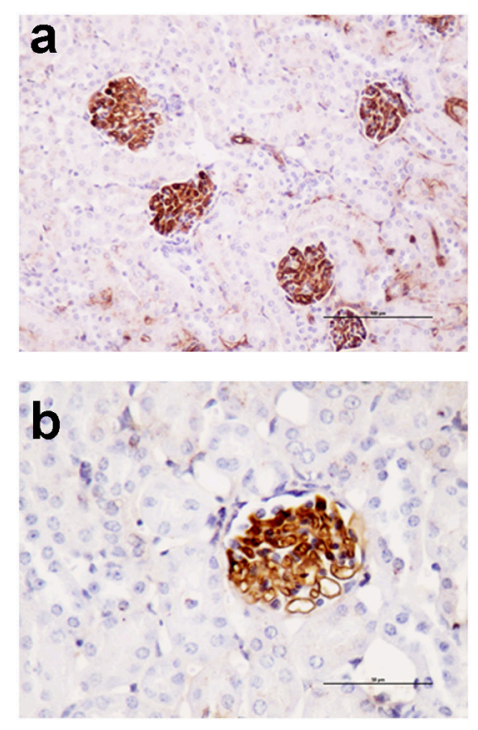
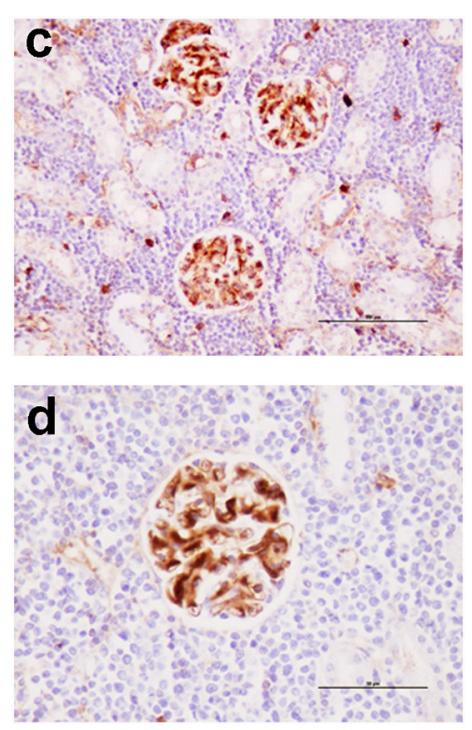
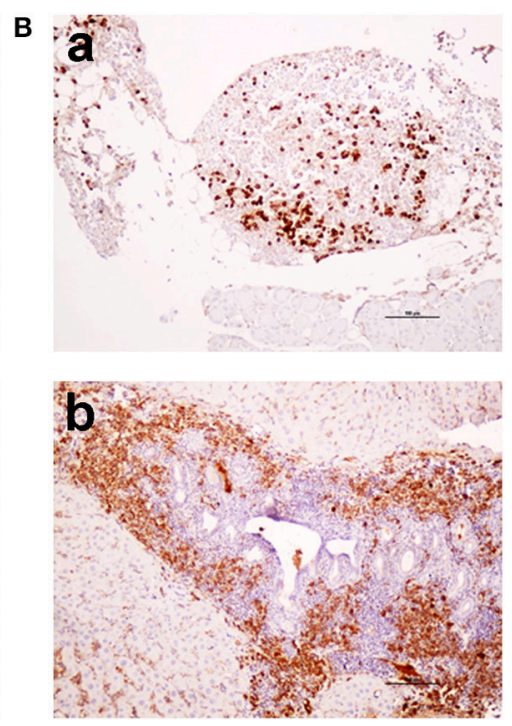

FIGURE 6 | TRAF3/BCL2 double-tg mice develop autoimmune features similar to the TRAF3-tg mice. (A) lgG depositions in glomeruli of TRAF3/BCL2 double-tg mice in samples showing an otherwise normal kidney architecture [(a), $100 \mathrm{x}$ and (b), $200 \mathrm{x}$ ] or showing heavy lymphocyte infiltration [(c), $100 \mathrm{x}$ and (d), $200 \mathrm{x}$. Microphotographs are from 4 representative TRAF3/BCL2 double-tg mice. Staining was performed with anti-mouse lgG-HRP. Scale bars are shown [(a,c), $100 \mu$ m; (b,d), $50 \mu \mathrm{m}$ ] (B). Tertiary lymphoid organs formation in the TRAF3/BCL2 double-tg mice. Two representative examples of tertiary lymphoid organs developed in two mice are shown. Panel (a) shows a tertiary lymphoid organ in the omentum. Plasma cells are shown by staining with anti-mouse IgG-HRP. Panel (b) shows lymphoid neogenesis in the liver, with a prominent presence of plasma cells. Staining was performed with anti-mouse IgG-HRP. Magnification was $100 \mathrm{x}$. Scale bars are shown $(100 \mu \mathrm{m})$.

might underline different TRAF3 requirements to activate the immune response in distinct $B$ cell types. Of note is that, as we previously reported (14), TRAF3 overexpression does not seems to alter the initiation of the humoral response, since the IgM response to TI and TD antigens is similar in TRAF3$\mathrm{tg}$ and wild-type mice. Instead, TRAF3 seems to control later stages of B cell differentiation, such as class switching and SHM and/or the duration of antibody responses, as indicated by the elevated IgG serum levels in the TRAF3-tg mice and the increased IgG production seen upon antigen challenge. Indeed, in further support of this idea, TRAF3-tg, and TRAF3/BCL2 double-tg B cells with $V_{H} D J_{H}$ rearrangements recognizing typical TI antigens, such as DNA and phosphatidylcholine, have gone through class switching and SHM (not shown). Furthermore, most of the DLBCL and plasma cell neoplasms developed by the TRAF3/BCL-2 double-tg mice are composed by expanded transformed clones that have also undergone class switching and SHM. This is true even for half of the expanded clones expressing IgM, which also show SHM. In contrast, the B cell neoplasms developed by the B cell-specific Traf3-deficient mice (28) were consistent with SBL/CLL and MZL, with over $86 \%$ of the expanded cloned having non-mutated $V_{H} D J_{H}$ regions (applying the $97.5 \%$ identity to the germ line criteria that we have used in our analyses).

Altogether, the present evidence allows speculation about whether TRAF3 overexpression might drive TI-antigen activated B cells through an ASC differentiation program that enforces the production of high-affinity, SHM, class-switched antibodies (49). In this scenario, TRAF3 might facilitate antigen-challenged
B cells to escape from the B tolerance surveillance mechanisms resulting in the production of autoreactive Ig clones (49). Indeed, it has been shown that high-affinity SHM IgG autoantibodies exacerbate SLE symptoms compared to IgM autoantibodies (50, 51 ), which is consistent with the presence of IgG depositions in the renal glomeruli of the TRAF3/BCL2 double-tg mice. Most interestingly, recent results suggest that B cell intrinsic type 1 IFN keeps BCR signaling beyond the threshold required for effective tolerance (52). As a result, type $1 \mathrm{IFN}$ would contribute to the loss of B cell tolerance and the development of autoreactive B cells into the GC and extra-follicular pathways. Thus, considering the key role of TRAF3 in the promotion of efficient type-1 IFN production in response to pathogen challenges, these results may underlie the role of TRAF3 in the development of the SLE (14). Altogether, these results further emphasize the differences between Traf3-defficiency and TRAF3 overexpression in B cell pathophysiology and underscore the need of keeping TRAF3 expression tightly regulated to assure normal B cell homeostasis and humoral responses to antigens.

Finally, while ample evidence exists about the role of deleterious TRAF3 mutations in the development of human $B$ cell neoplasia [which presumably is the result, at least in part, of the activation of NF- $\kappa \mathrm{B} 2$-mediated transcriptional programs (21-28)], little is known about whether TRAF3 upregulation also plays a role in human lymphoid tumorigenesis (53). While genomic analysis has not revealed TRAF3 gene amplification in lymphoid malignancies, epigenetic mechanisms could contribute to elevated TRAF3 expression. Alternatively, a gain of TRAF3 protein function could instead be caused by 
modifications of either the expression or the activity of any of the abundant proteins involved in TRAF3 regulation $(54,55)$. Besides, as shown in this article, TRAF3 overexpression in $\mathrm{B}$ cells is not sufficient to induced B cell transformation and requires additional partners to facilitate $\mathrm{B}$ cell transformation. In summary, the results presented herein are consistent with a scenario in which TRAF3 overexpression or gain-offunction causes the anomalous selection and differentiation of PRR-co-stimulated B cell clones that in combination with BCL2 over-expression predisposes to malignant B cell transformation.

\section{AUTHOR CONTRIBUTIONS}

JZ and GP-C designed research; GP-C, SL, MV-C, and JZ performed experiments; GP-C, MA, and JZ analyzed data; JR provided essential reagents; JZ, GP-C, MA, and JR interpreted and discussed the data; JZ wrote the paper.

\section{FUNDING}

Funding was from Instituto de Salud Carlos III (ISCIII) PI080170, PI12/01135, and PI16/00895 to JZ and from the National Institutes of Health (AI070859 to JZ and CA163743 to JR). The cost of this publication was paid in part by the CSIC

\section{REFERENCES}

1. Xie P. TRAF molecules in cell signaling and in human diseases. J Mol Signal. (2013) 8:7. doi: 10.1186/1750-2187-8-7

2. Zapata JM, Lefebvre S, Reed JC. Targeting TRAFs for therapeutic intervention. Adv Exp Med Biol. (2007) 597:188-201. doi: 10.1007/978-0-387-70630-6_15

3. Hildebrand JM, Yi Z, Buchta CM, Poovassery J, Stunz LL, Bishop GA. Roles of tumor necrosis factor receptor associated factor 3 (TRAF3) and TRAF5 in immune cell functions. Immunol Rev. (2011) 244:55-74. doi: 10.1111/j.1600-065X.2011.01055.x

4. Yi Z, Lin WW, Stunz LL, Bishop GA. Roles for TNF-receptor associated factor 3 (TRAF3) in lymphocyte functions. Cytokine Growth Factor Rev. (2014) 25:147-56. doi: 10.1016/j.cytogfr.2013.12.002

5. Rickert RC, Jellusova J, Miletic AV. Signaling by the tumor necrosis factor receptor superfamily in B-cell biology and disease. Immunol Rev. (2011) 244:115-33. doi: 10.1111/j.1600-065X.2011. 01067.x

6. Tseng PH, Matsuzawa A, Zhang W, Mino T, Vignali DA, Karin M. Different modes of ubiquitination of the adaptor TRAF3 selectively activate the expression of type I interferons and proinflammatory cytokines. Nat Immunol. (2010) 11:70-5. doi: 10.1038/ni.1819

7. Oganesyan G, Saha SK, Guo B, He JQ, Shahangian A, Zarnegar B, et al. Critical role of TRAF3 in the Toll-like receptor-dependent and -independent antiviral response. Nature (2006) 439:208-11. doi: 10.1038/nature04374

8. Hacker H, Redecke V, Blagoev B, Kratchmarova I, Hsu LC, Wang GG, et al. Specificity in Toll-like receptor signalling through distinct effector functions of TRAF3 and TRAF6. Nature (2005) 439:204-7. doi: 10.1038/nature04369

9. Cai X, Du J, Liu Y, Xia W, Liu J, Zou M, et al. Identification and characterization of receptor-interacting protein 2 as a TNFR-associated factor 3 binding partner. Gene (2013) 517:205-11. doi: 10.1016/j.gene.2012.12.026

10. Guan K, Wei C, Zheng Z, Song T, Wu F, Zhang Y, et al. MAVS Promotes inflammasome activation by targeting ASC for K63-linked ubiquitination via the E3 ligase TRAF3. J Immunol. (2015) 194:4880-90. doi: 10.4049/jimmunol.1402851
Open Access Publication Support Initiative through its Unit of Information Resources for Research (URICI) and by funds from the European Fund for Economic and Regional Development (FEDER).

\section{ACKNOWLEDGMENTS}

We are indebted to the excellent technical support of Maria G. Gonzalez-Bueno, Christina L Kress, and Andrea de Andres. We are grateful to the personnel of the Comparative Medicine, Genomics and Histology facilities at Instituto de Investigaciones Biomedicas Alberto Sols (Madrid), to the personnel of the Animal and Histology facilities at Sanford Burnham Prevys Medical Discovery Institute (La Jolla, CA), to the personnel of the Immunohistochemistry laboratory at IdiPaz (Madrid) and to the personnel of the Flow Cytometry Service at SIDI (UAM, Madrid). We also thank Dr. Paloma Perez-Aciego (LAIR Foundation, Madrid, Spain) and Dr. Ping Xie (Rutgers Cancer Institute, NJ) for kindly providing reagents and for helpful discussions.

\section{SUPPLEMENTARY MATERIAL}

The Supplementary Material for this article can be found online at: https://www.frontiersin.org/articles/10.3389/fimmu. 2018.03114/full\#supplementary-material

11. Saleh M. The machinery of Nod-like receptors: refining the paths to immunity and cell death. Immunol Rev. (2011) 243:235-46. doi: 10.1111/j.1600-065X.2011.01045.x

12. Zhu S, Pan W, Shi P, Gao H, Zhao F, Song $\mathrm{X}$, et al. Modulation of experimental autoimmune encephalomyelitis through TRAF3-mediated suppression of interleukin 17 receptor signaling. J Exp Med. (2010) 207:264762. doi: 10.1084/jem.20100703

13. Xie P, Stunz LL, Larison KD, Yang B, Bishop GA. Tumor necrosis factor receptor-associated factor 3 is a critical regulator of $\mathrm{B}$ cell homeostasis in secondary lymphoid organs. Immunity (2007) 27:253-67. doi: 10.1016/j.immuni.2007.07.012

14. Zapata JM, Llobet D, Krajewska M, Lefebvre S, Kress CL, Reed JC. Lymphocyte-specific TRAF3 transgenic mice have enhanced humoral responses and develop plasmacytosis, autoimmunity, inflammation, and cancer. Blood (2009) 113:4595-603. doi: 10.1182/blood-2008-07165456

15. Sun SC. Non-canonical NF-kappaB signaling pathway. Cell Res. (2011) 21:7185. doi: $10.1038 / \mathrm{cr} .2010 .177$

16. Lin WW, Hildebrand JM, Bishop GA. A Complex Relationship between TRAF3 and Non-Canonical NF-kappaB2 Activation in B Lymphocytes. Front Immunol. (2013) 4:477. doi: 10.3389/fimmu.2013. 00477

17. Gardam S, Sierro F, Basten A, Mackay F, Brink R. TRAF2 and TRAF3 signal adapters act cooperatively to control the maturation and survival signals delivered to B cells by the BAFF receptor. Immunity (2008) 28:391-401. doi: 10.1016/j.immuni.2008.01.009

18. Xie P, Poovassery J, Stunz LL, Smith SM, Schultz ML, Carlin LE, et al. Enhanced Toll-like receptor (TLR) responses of TNFR-associated factor 3 (TRAF3)-deficient B lymphocytes. J Leukoc Biol. (2011) 90:1149-57. doi: 10.1189/jlb.0111044

19. Krajewski S, Zapata JM, Krajewska M, VanArsdale T, Shabaik A, Gascoyne RD, et al. Immunohistochemical analysis of in vivo patterns of TRAF-3 expression, a member of the TNF receptor-associated factor family. J Immunol. (1997) 159:5841-52. 
20. Lopes-Carvalho T, Kearney JF. Marginal zone B cell physiology and disease. Curr Dir Autoimmun. (2005) 8:91-123. doi: 10.1159/000082100

21. Puente XS, Bea S, Valdes-Mas R, Villamor N, Gutierrez-Abril J, Martin-Subero JI, et al. Non-coding recurrent mutations in chronic lymphocytic leukaemia. Nature (2015) 526:519-24. doi: 10.1038/nature14666

22. Rossi D, Deaglio S, Dominguez-Sola D, Rasi S, Vaisitti T, Agostinelli C, et al. Alteration of BIRC3 and multiple other NF-kappaB pathway genes in splenic marginal zone lymphoma. Blood (2011) 118:4930-4. doi: 10.1182/blood-2011-06-359166

23. Keats JJ, Fonseca R, Chesi M, Schop R, Baker A, Chng WJ, et al. Promiscuous mutations activate the noncanonical NF-kappaB pathway in multiple myeloma. Cancer Cell (2007) 12:131-44. doi: 10.1016/j.ccr.2007.07.003

24. Annunziata CM, Davis RE, Demchenko Y, Bellamy W, Gabrea A, Zhan F, et al. Frequent engagement of the classical and alternative NF-kappaB pathways by diverse genetic abnormalities in multiple myeloma. Cancer Cell (2007) 12:115-30. doi: 10.1016/j.ccr.2007.07.004

25. Braggio E, Keats JJ, Leleu X, Van Wier S, Jimenez-Zepeda VH, Valdez $\mathrm{R}$, et al. Identification of copy number abnormalities and inactivating mutations in two negative regulators of nuclear factor-kappaB signaling pathways in Waldenstrom's macroglobulinemia. Cancer Res. (2009) 69:357988. doi: 10.1158/0008-5472.CAN-08-3701

26. Nagel I, Bug S, Tonnies H, Ammerpohl O, Richter J, Vater I, et al. Biallelic inactivation of TRAF3 in a subset of B-cell lymphomas with interstitial del(14)(q24.1q32.33). Leukemia (2009) 23:2153-5. doi: 10.1038/leu.2009.149

27. Bushell KR, Kim Y, Chan FC, Ben-Neriah S, Jenks A, Alcaide M, et al. Genetic inactivation of TRAF3 in canine and human B-cell lymphoma. Blood (2015) 125:999-1005. doi: 10.1182/blood-2014-10-602714

28. Moore CR, Liu Y, Shao C, Covey LR, Morse HC III, Xie P. Specific deletion of TRAF3 in B lymphocytes leads to B-lymphoma development in mice. Leukemia (2012) 26:1122-7. doi: 10.1038/leu.2011.309

29. Reeves WH, Lee PY, Weinstein JS, Satoh M, Lu L. Induction of autoimmunity by pristane and other naturally occurring hydrocarbons. Trends Immunol. (2009) 30:455-64. doi: 10.1016/j.it.2009.06.003

30. Gado K, Silva S, Paloczi K, Domjan G, Falus A. Mouse plasmacytoma: an experimental model of human multiple myeloma. Haematologica (2001) 86:227-36.

31. Zapata JM, Krajewska M, Morse HC III, Choi Y, Reed JC. TNF receptorassociated factor (TRAF) domain and Bcl-2 cooperate to induce small B cell lymphoma/chronic lymphocytic leukemia in transgenic mice. Proc Natl Acad Sci USA. (2004) 101:16600-5. doi: 10.1073/pnas.0407541101

32. Perez-Chacon G, Llobet D, Pardo C, Pindado J, Choi Y, Reed JC, et al. TNFR-associated factor 2 deficiency in B lymphocytes predisposes to chronic lymphocytic leukemia/small lymphocytic lymphoma in mice. J Immunol. (2012) 189:1053-61. doi: 10.4049/jimmunol.1200814

33. Huang J, Fairbrother W, Reed JC. Therapeutic targeting of Bcl-2 family for treatment of B-cell malignancies. Expert Rev Hematol. (2015) 8:283-97. doi: 10.1586/17474086.2015.1026321

34. Schuetz JM, Johnson NA, Morin RD, Scott DW, Tan K, Ben-Nierah S, et al. BCL2 mutations in diffuse large B-cell lymphoma. Leukemia (2012) 26:1383-90. doi: 10.1038/leu.2011.378

35. Katsumata M, Siegel RM, Louie DC, Miyashita T, Tsujimoto Y, Nowell PC, et al. Differential effects of Bcl-2 on B and T lymphocytes in transgenic mice. Proc Natl Acad Sci USA (1992) 89:11376-80. doi: 10.1073/pnas.89.23.11376

36. Reed J, Meister L, Cuddy M, Geyer C, Pleasure D. Differential expression of the $\mathrm{Bcl}-2$ proto-oncogene in neuroblastoma and other human tumor cell lines of neural origin. Cancer Res. (1991) 51:6529-38.

37. Brochet X, Lefranc MP, Giudicelli V. IMGT/V-QUEST: the highly customized and integrated system for IG and TR standardized V-J and V-D-J sequence analysis. Nucleic Acids Res. (2008) 36:W503-8. doi: 10.1093/nar/ gkn316

38. Giudicelli V, Brochet X, Lefranc MP. IMGT/V-QUEST: IMGT standardized analysis of the immunoglobulin (IG) and $\mathrm{T}$ cell receptor (TR) nucleotide sequences. Cold Spring Harbor Protocol. (2011) 2011:695-715. doi: 10.1101/pdb.prot5633

39. Yan XJ, Albesiano E, Zanesi N, Yancopoulos S, Sawyer A, Romano E, et al. $\mathrm{B}$ cell receptors in TCL1 transgenic mice resemble those of aggressive, treatment-resistant human chronic lymphocytic leukemia. Proc Natl Acad Sci USA. (2006) 103:11713-8. doi: 10.1073/pnas.0604564103
40. Johannessen M, Delghandi MP, Moens U. What turns CREB on? Cell Signal. (2004) 16:1211-27. doi: 10.1016/j.cellsig.2004.05.001

41. Pasqualucci L, Dalla-Favera R. Genetics of diffuse large B-cell lymphoma. Blood (2018) 131:2307-19. doi: 10.1182/blood-2017-11-764332

42. Garcia-Ramirez I, Tadros S, Gonzalez-Herrero I, Martin-Lorenzo A, Rodriguez-Hernandez G, Moore D, et al. Crebbp loss cooperates with Bcl2 overexpression to promote lymphoma in mice. Blood (2017) 129:2645-56. doi: 10.1182/blood-2016-08-733469

43. Hacker $\mathrm{H}$, Tseng PH, Karin M. Expanding TRAF function: TRAF3 as a tri-faced immune regulator. Nat Rev Immunol. (2011) 11:457-68. doi: $10.1038 /$ nri2998

44. van Zuylen WJ, Doyon P, Clement JF, Khan KA, D'Ambrosio LM, Do F, et al. Proteomic profiling of the TRAF3 interactome network reveals a new role for the ER-to-Golgi transport compartments in innate immunity. PLoS Pathog. (2012) 8:e1002747. doi: 10.1371/journal.ppat.10 02747

45. Guven-Maiorov E, Keskin O, Gursoy A, VanWaes C, Chen Z, Tsai CJ, et al. TRAF3 signaling: competitive binding and evolvability of adaptive viral molecular mimicry. Biochim Biophys Acta (2016) 1860(11 Pt B):2646-55. doi: 10.1016/j.bbagen.2016.05.021

46. Bangalore-Prakash P, Stunz LL, Mambetsariev N, Whillock AL, Hostager BS, Bishop GA. The oncogenic membrane protein LMP1 sequesters TRAF3 in B-cell lymphoma cells to produce functional TRAF3 deficiency. Blood Adv. (2017) 1:2712-23. doi: 10.1182/bloodadvances.2017009670

47. DeFranco AL, Rookhuizen DC, Hou B. Contribution of Toll-like receptor signaling to germinal center antibody responses. Immunol Rev. (2012) 247:6472. doi: 10.1111/j.1600-065X.2012.01115.x

48. Hou B, Saudan P, Ott G, Wheeler ML, Ji M, Kuzmich L, et al. Selective utilization of Toll-like receptor and MyD88 signaling in B cells for enhancement of the antiviral germinal center response. Immunity (2011) 34:375-84. doi: 10.1016/j.immuni.2011.01.011

49. Brink R, Phan TG. Self-reactive $B$ cells in the germinal center reaction. Annu Rev Immunol. (2018) 36:339-57. doi: 10.1146/annurev-immunol-051116-052510

50. Jackson SW, Kolhatkar NS, Rawlings DJ. B cells take the front seat: dysregulated B cell signals orchestrate loss of tolerance and autoantibody production. Curr Opin Immunol. (2015) 33:70-7. doi: 10.1016/j.coi.2015.01.018

51. Rawlings DJ, Metzler G, Wray-Dutra M, Jackson SW. Altered B cell signalling in autoimmunity. Nat Rev Immunol. (2017) 17:421-36. doi: 10.1038/nri.2017.24

52. Domeier PP, Chodisetti SB, Schell SL, Kawasawa YI, Fasnacht MJ, Soni C, et al. B-cell-intrinsic type 1 interferon signaling is crucial for loss of tolerance and the development of autoreactive B cells. Cell Reports (2018) 24:406-18. doi: 10.1016/j.celrep.2018.06.046

53. Muro I, Fang G, Gardella KA, Mahajan IM, Wright CW. The TRAF3 adaptor protein drives proliferation of anaplastic large cell lymphoma cells by regulating multiple signaling pathways. Cell Cycle (2014) 13:1918-27. doi: $10.4161 /$ cc. 28895

54. Lin WW, Hostager BS, Bishop GA. TRAF3, ubiquitination, and Blymphocyte regulation. Immunol Rev. (2015) 266:46-55. doi: 10.1111/imr. 12299

55. Lin $\mathrm{D}$, Zhang $\mathrm{M}$, Zhang MX, Ren $\mathrm{Y}$, Jin J, Zhao Q, et al. Induction of USP 25 by viral infection promotes innate antiviral responses by mediating the stabilization of TRAF3 and TRAF6. Proc Natl Acad Sci USA. (2015) 112:11324-9. doi: 10.1073/pnas.1509968112

Conflict of Interest Statement: The authors declare that the research was conducted in the absence of any commercial or financial relationships that could be construed as a potential conflict of interest.

Copyright (c) 2019 Perez-Chacon, Adrados, Vallejo-Cremades, Lefebvre, Reed and Zapata. This is an open-access article distributed under the terms of the Creative Commons Attribution License (CC BY). The use, distribution or reproduction in other forums is permitted, provided the original author(s) and the copyright owner(s) are credited and that the original publication in this journal is cited, in accordance with accepted academic practice. No use, distribution or reproduction is permitted which does not comply with these terms. 